\title{
Colorado Family Physicians’ Attitudes Toward Medical Marijuana
}

\author{
Elin Kondrad, MD, and Alfred Reid, $M A$
}

Introduction: Over the last decade, the use of medical marijuana has expanded dramatically; it is now permitted in 16 states and the District of Columbia. Our study of family physicians in Colorado is the first to gather information about physician attitudes toward this evolving practice.

Methods: We distributed an anonymous web-based electronic survey to the 1727 members of the Colorado Academy of Family Physicians' listserv. Items included individual and practice characteristics as well as experience with and attitudes toward medical marijuana.

Results: Five hundred twenty family physicians responded (30\% response rate). of these, $46 \%$ did not support physicians recommending medical marijuana; only 19\% thought that physicians should recommend it. A minority thought that marijuana conferred significant benefits to physical (27\%) and mental (15\%) health. Most agreed that marijuana poses serious mental (64\%) and physical (61\%) health risks. Eighty-one percent agreed that physicians should have formal training before recommending medical marijuana, and $\mathbf{9 2 \%}$ agreed that continuing medical education about medical marijuana should be available to family physicians.

Conclusions: Despite a high prevalence of use in Colorado, most family physicians are not convinced of marijuana's health benefits and believe its use carries risks. Nearly all agreed on the need for further medical education about medical marijuana. (J Am Board Fam Med 2013;26:52-60.)

Keywords: Attitudes, Cannabis, Marijuana, Medical Education

In November 2000, Colorado passed Amendment 20, which provides an affirmative defense for the use and possession of marijuana by people with one of the following 8 "debilitating medical conditions": HIV/ AIDS, glaucoma, severe nausea, severe pain, cancer, cachexia, seizures, and muscle spasms. ${ }^{1}$ To obtain a medical marijuana registry card, patients must complete an application that includes a physician certification that may be completed by any Colorado-licensed physician, attesting that they have one of the above conditions and may benefit from the use of

This article was externally peer reviewed.

Submitted 24 March 2012; revised 27 August 2012; accepted 10 September 2012.

From the St. Anthony North Family Medicine Residency, Westminster, CO (EK); and the Department of Family Medicine, University of North Carolina, Chapel Hill, NC (AR).

Funding: This research was supported by the University of North Carolina Department of Family Medicine Faculty Development Fellowship and in-kind support from St. Anthony North Family Medicine Residency.

Conflict of interest: none declared.

Corresponding author: Elin Kondrad, St. Anthony North Family Medicine Residency, 8510 Bryant St, Suite 210, Westminster, CO 80031 (E-mail: elinkondrad@centura.org). medical marijuana. In October 2009, the US Department of Justice issued a directive that it would not pursue federal prosecution against people who comply with state laws allowing possession of marijuana for medical purposes. ${ }^{2}$ After this announcement, applications to Colorado's medical marijuana registry increased from 300 per month to 1000 per day. Colorado now leads the nation in per-capita medical marijuana registrants; Colorado physicians have recommended marijuana for an estimated 163,856 patients, more than $2 \%$ of Colorado's population. ${ }^{1} \mathrm{Col}-$ orado has seen a dramatic increase in the number of marijuana dispensaries-brick and mortar shops where patients may purchase marijuana in various forms once they have a medical marijuana registry card-and leads the nation in per-capita dispensaries, with more than 800 in the state. ${ }^{3}$ As of December 31, 2011, the date of the most recent statistics published by the Colorado Department of Public Health and the Environment, 94\% of registrants were using medical marijuana for chronic pain and $17 \%$ for muscle spasms (a patient may be registered for multiple conditions) ${ }^{1}$ 
Despite the dramatic increase in the use of smoked medical marijuana, there are few clinical trials demonstrating its benefits. Several studies found that smoked marijuana was superior to placebo for acute pain, chronic neuropathic pain, chemotherapy-induced nausea and vomiting, and cachexia associated with HIV. ${ }^{4-13}$ However, the generalizability of these studies is limited by the small numbers of subjects enrolled (between 5 and 67), the lack of dose standardization of the active compounds in the smoked marijuana used in the studies, and the difficulty blinding participants. Other studies of smoked marijuana for these conditions have shown either no significant benefit or exacerbation by marijuana of the condition being studied. ${ }^{9,14,15}$ The Institute of Medicine report Marijuana and Medicine: Assessing the Science Base concluded that "scientific data indicate the potential therapeutic value of cannabinoid drugs, primarily THC, for pain relief, control of nausea and vomiting, and appetite stimulation; smoked marijuana, however, is a crude THC delivery system that also delivers harmful substances." 16

Substantial concerns remain about marijuana's adverse effects. Acute effects of marijuana use include sedation, dizziness, anxiety, and psychosis. ${ }^{17}$ Nine percent of users develop dependence, including impaired control over use, difficulty stopping marijuana use despite its harms, and development of a withdrawal syndrome when use is discontinued. ${ }^{18}$ Regular users are more likely to use other drugs, including cocaine and heroin, particularly when they initiate use of marijuana as adolescents. ${ }^{18}$ Marijuana users also experience cognitive deficits, which manifest as dose-related impairments in reaction time, information processing, motor performance, and attention. ${ }^{17}$ Heavy users report decreases in verbal learning, memory, and attention; it is unclear whether and how quickly these deficits resolve after stopping marijuana use. In addition, marijuana use is associated with a doubled risk of developing schizophrenia. ${ }^{18}$ Among users who already have psychotic disorders, ongoing marijuana use is associated with increased psychotic symptoms. ${ }^{19}$ Use of cannabis during adolescence also is associated with an increased risk for depressive disorders as well as attempted and completed suicide. ${ }^{20}$ Finally, long-term marijuana smoking is associated with increased respiratory symptoms suggestive of obstructive lung disease, ${ }^{21}$ and the use of both marijuana and tobacco seems to increase symptoms of obstructive lung disease synergistically. ${ }^{22}$

Although there is limited high-quality evidence for the medical benefits of smoked marijuana, it is permitted for medicinal use in states that comprise more than $25 \%$ of the US population. Although medical opinion and expertise should be one of the major forces informing legislation for medical marijuana, Colorado's Amendment 20, and similar legislation in other states, passed with little consideration of physicians' attitudes toward medical marijuana.

Indeed, we have little information about how doctors nationwide feel about either the use of marijuana as a medicine or the role of physicians in recommending marijuana to patients. A 1989 physician survey regarding outright legalization of marijuana found that $41 \%$ of respondents were in favor of legalization, but it did not address marijuana use for medical purposes. ${ }^{23}$ A 2005 survey of 960 physicians from multiple specialties found that physicians generally were less supportive of medical marijuana use than the general public. ${ }^{24}$ A survey of oncologists found that $30 \%$ supported rescheduling of marijuana for medical purposes by the Drug Enforcement Administration. ${ }^{25}$ Another study of oncologists reported that $54 \%$ of oncologists surveyed agreed that marijuana should be available by prescription. ${ }^{26}$ Even though primary care physicians provide much of the health care for patients with the conditions for which marijuana is largely being recommended, namely chronic pain and muscle spasms, there are no studies that focus on primary care physicians and their attitudes toward medical marijuana.

This article presents the results of a survey that asked family physicians in the state of Colorado about their attitudes toward medical marijuana in general and as currently practiced in Colorado. We chose to carry out this survey in Colorado because of the high rates of medical marijuana use and because it is one of the few states that compiles and publicly releases statistics about the people who apply to the state's medical marijuana registry. Although Colorado has some outspoken physician proponents and detractors of medical marijuana represented in the media, there still are no data that capture the attitudes of most practicing physicians who have the opportunity to recommend medical marijuana. Furthermore, the vast majority of patients on the Colorado medical marijuana registry have had marijuana recommended to them by one 
of a small number of physicians: $49 \%$ of recommendations have been made by only 15 physicians. $^{27}$ There is little information about whether and how often most primary care providers are recommending medical marijuana. The aims of our survey were to gather information that may inform policies regulating medical marijuana and to evaluate the need for further medical education on this relatively new and rapidly growing area of medical practice.

\section{Methods}

We distributed an online survey to the $1727 \mathrm{mem}$ bers of the Colorado Academy of Family Physicians (CAFP) in January 2011. Each subject received an E-mail reminder to complete the survey 2 weeks after the initial distribution and another reminder 4 weeks after initial distribution.

The 3-part survey began with demographic information, including age, sex, years in practice, and whether the subject had an unrestricted medical license. The second part dealt with respondents' experience with medical marijuana, including whether they had ever recommended medical marijuana to a patient, how many times, and for which medical conditions; which factors most influenced their decision to recommend medical marijuana; and from which sources they obtained most of their information about medical marijuana. In the third part, respondents were asked to rate, on a 5-point Likert scale, the extent to which they agreed or disagreed with 17 statements about marijuana policy in Colorado and nationally (including legalization of marijuana for recreational use, reclassifying marijuana from schedule I, and distribution of medical marijuana through a dispensary model); the risks and benefits of marijuana use; and educational opportunities about marijuana at various levels of medical training. An open-ended item asked for any other comments regarding medical marijuana.

Survey items were reviewed for construct validity by 6 family physicians and a psychologist and were pilot-tested by 18 family physicians and a psychiatrist before distribution. The study protocol and survey instrument were approved by the St. Anthony Hospital Institutional Review Board. No external funding was received for this study.

Numerical responses were tabulated and summarized using counts and percentages. To facilitate bivariate comparisons, we collapsed responses to the 17 Likert scale items into "agree" (agree and strongly agree) and "disagree" (disagree and strongly disagree), excluding "neither agree nor disagree." We then compared the responses of those who had recommended marijuana for a patient with those who had not using the $\chi^{2}$ test for independence. Open-ended comments were reviewed for common themes, which then were tabulated and sorted by frequency.

\section{Results}

A total of 520 responses were obtained, for a response rate of $30 \%$. Table 1 summarizes respondents' ages and sex compared with the overall membership of the CAFP.

Of the physicians surveyed, $31 \%$ reported ever recommending medical marijuana to a patient. Of these, the majority (71\%) had recommended medical marijuana to between 1 and 5 patients. Only $1 \%$ (2 physicians) had recommended medical marijuana to more than 50 patients, and none had recommended marijuana to more than $100 \mathrm{pa}$ tients. Figure 1 summarizes survey respondents' reasons for recommending marijuana to a patient compared with reasons that patients are on the Colorado medical marijuana registry. Figure 2 identifies the sources where physicians reported getting most of their information about medical marijuana. Significantly more respondents who had not recommended marijuana for a patient cited

\section{Table 1. Demographics of All Colorado Academy of Family Physicians (CAFP) Members vs Survey Respondents}

\begin{tabular}{ccc}
\hline & Survey Respondents & CAFP Members \\
\hline $\begin{array}{c}\text { Age, years } \\
20-29\end{array}$ & $41(8)$ & \\
$30-39$ & $87(17)$ & $243(12)$ \\
$40-49$ & $152(30)$ & $448(23)$ \\
$50-59$ & $161(32)$ & $499(25)$ \\
$60-69$ & $65(13)$ & $464(23)$ \\
$\geq 70$ & $5(1)$ & $206(10)$ \\
Sex & & $98(5)$ \\
Male & $284(56)$ & $1078(54)$ \\
Female & $224(44)$ & $913(46)$ \\
\hline
\end{tabular}

Values provided as $\mathrm{n}$ (\%). Distribution of survey respondents did not differ significantly from the CAFP membership by age category or sex. 
Figure 1. Indications for which family physicians (FPs) are recommending medical marijuana compared with reasons that patients are in the Colorado medical marijuana registry. Medical conditions listed on the left are the 8 approved conditions for which physicians can recommend medical marijuana in Colorado. "Registry patients" indicates percentages of patients on the Colorado state medical marijuana registry for each indication shown, according to the Colorado Department of Public Health and the Environment. "Surveyed FPs" indicates the percentage of survey respondents who had recommended medical marijuana for each indication (only the $31 \%$ of physicians who had recommended marijuana to a patient were asked to answer this question).

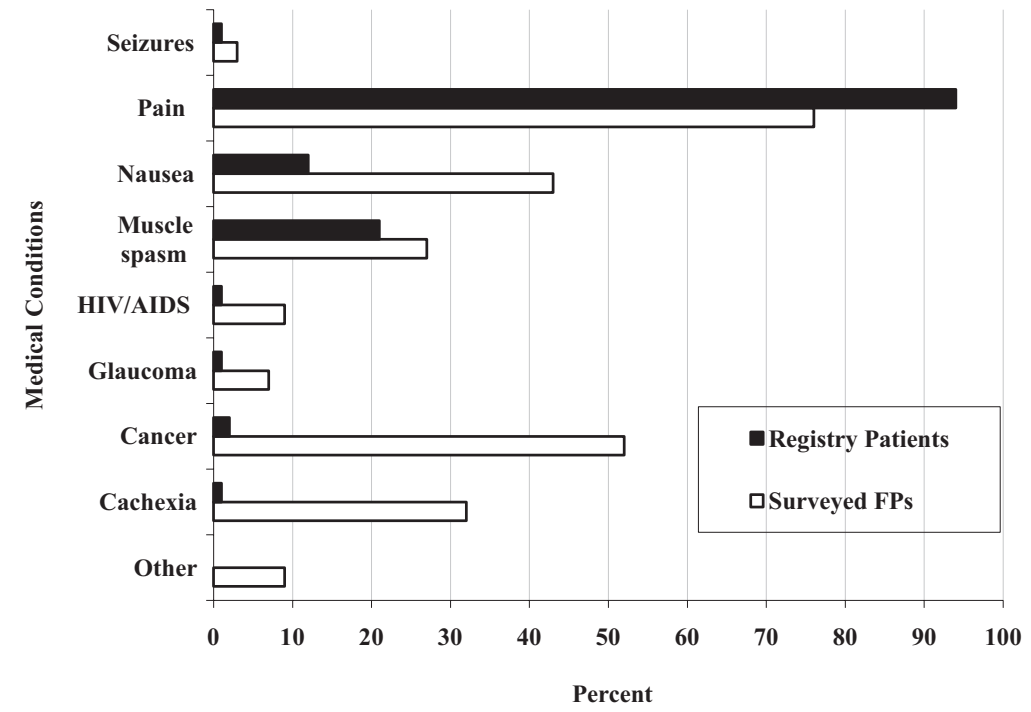

news media and practice policy as sources of information.

Figure 3 identifies the factors that most influenced decisions about recommending medical marijuana to patients. Consistent with information sources, significantly more respondents who have not recommended marijuana for patients cited news media and practice policy; they also more frequently cited dispensary owners and recreational use by friends and family. This group also identified "other" influences significantly more frequently, which included personal opinion (35\%), concerns about legal liability or licensure $(23 \%)$, and lack of evidence (13\%). Among respondents who had recommended marijuana for a patient, significantly more cited medical use by friends and family.

Of responding physicians, $46 \%$ said that physicians should not recommend marijuana as a medical therapy at all; 19\% agreed that physicians should recommend medical marijuana. Most physicians surveyed agreed that there were significant physical (61\%) and mental (64\%) health risks with marijuana use. Only a minority of physicians surveyed disagreed that there were significant physical $(18 \%)$ and mental (15\%) health risks with mari- juana use. When asked about benefits of marijuana use, $27 \%$ of those surveyed agreed that there were significant physical health benefits, while $41 \%$ disagreed. Fifteen percent agreed there were significant mental health benefits, while 54\% disagreed.

Regarding federal and state policies about marijuana, roughly equal numbers of respondents favored $(37 \%)$ or disfavored (44\%) the Drug Enforcement Administration reclassifying marijuana so that it is no longer a schedule I drug. Thirty percent of surveyed physicians agreed that marijuana should be legalized for recreational use and $50 \%$ disagreed. In addition, $76 \%$ of those surveyed agreed that medical marijuana should be included in Colorado's Physician Drug Monitoring Program, a secure, online database that tracks prescriptions for controlled substances.

Concerning the role of physicians in recommending medical marijuana, $92 \%$ of respondents agreed that doctors should have ongoing relationships with patients for whom they recommend medical marijuana, a stipulation that was not incorporated into law until June 2010, when Colorado Senate Bill 109 was enacted, requiring that doctors consult about the debilitating medical condition before the patient applies for a registry card, per- 
Figure 2. Sources of information about medical marijuana indicated by survey respondents, broken down by whether respondents had recommended medical marijuana for a patient. *Difference in proportions is statistically significant $(P<0.01)$. CME, continuing medical education.

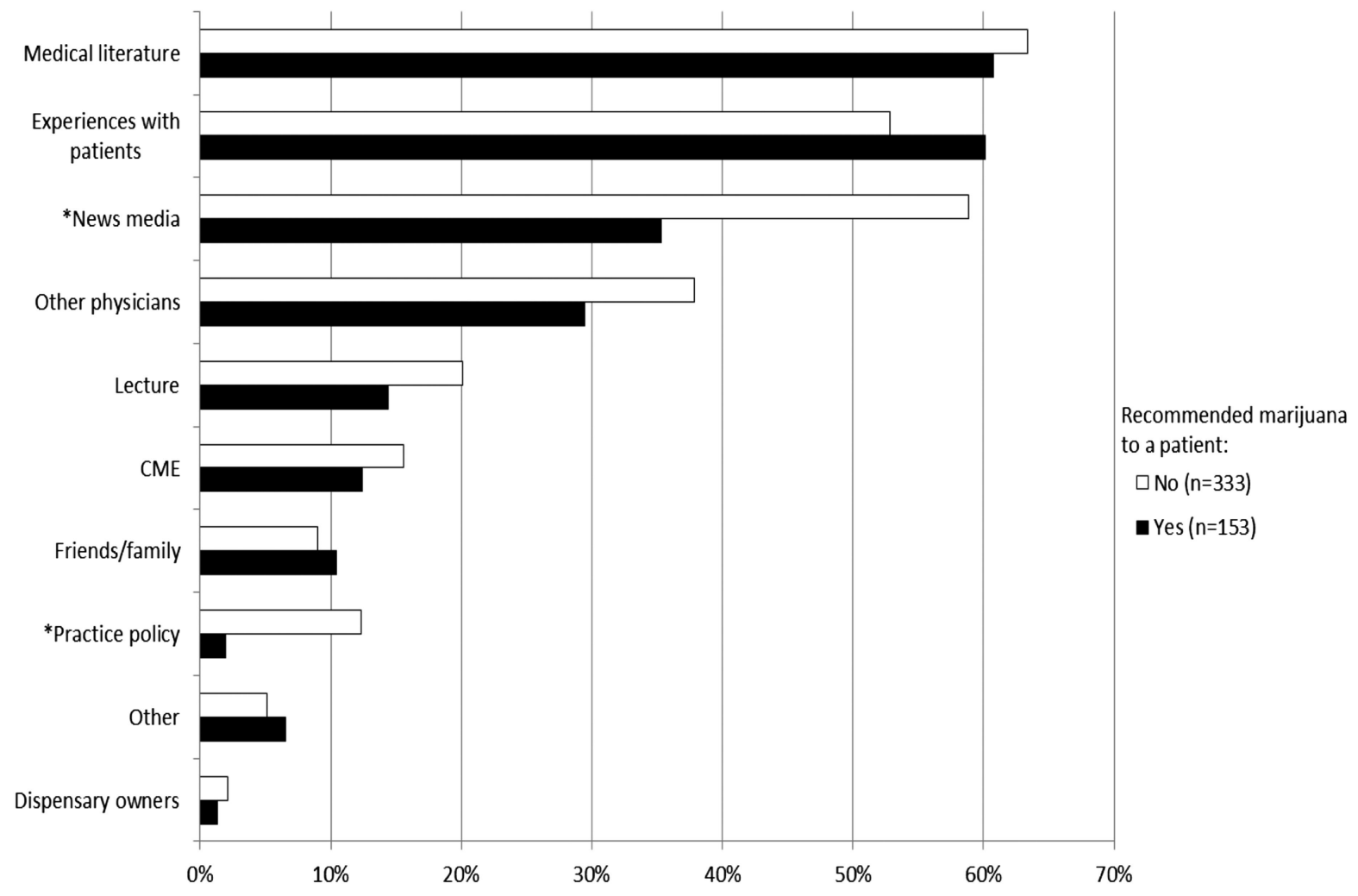

form a history and physical on the patient, and be available to provide follow-up care to the patient. ${ }^{28}$ Only $2 \%$ of those surveyed disagreed. Similarly, $95 \%$ of respondents agreed that doctors should not be permitted to have financial relationships with marijuana dispensaries, which was forbidden by Senate Bill 109. Sixty-three percent of respondents believed medical marijuana should not be available through the current dispensary system; only $10 \%$ of respondents favored the current dispensary model.

There was widespread agreement about the need for further medical education and training on medical marijuana: $80 \%$ agreed that training should be incorporated into medical school curricula, and $82 \%$ felt it should be a part of family medicine residency curricula; $92 \%$ agreed that continuing medical education (CME) about medical marijuana should be made available to primary care physicians, and $81 \%$ agreed that physicians should be required to have formal training about medical marijuana before recommending it to patients.
There was no significant association with physician sex, years in practice, or type of license and recommendation of medical marijuana. Age was significantly associated with recommendation of medical marijuana because of the substantially greater proportion of those aged 20 to 29 who had not recommended it.

There were differences in opinion between those physicians who had recommended medical marijuana to a patient compared with those who had not, as shown in Table 2. Those who had recommended medical marijuana were more likely to be convinced of its benefits and less concerned about its risks. It should be noted, however, that only 4 items in Table 2 reflect opposing opinions; in most cases, differences reflect significantly different proportions of agreement. There were no significant differences between the groups when asked whether medical marijuana should be included in the state database for monitoring controlled substances, whether doctors should have ongoing relationships with their patients, whether 
Figure 3. Influences on the decision to recommend or not recommend medical marijuana to a patient, as reported by survey respondents. *Difference in proportions is statistically significant $(P<0.01)$. CME, continuing medical education.

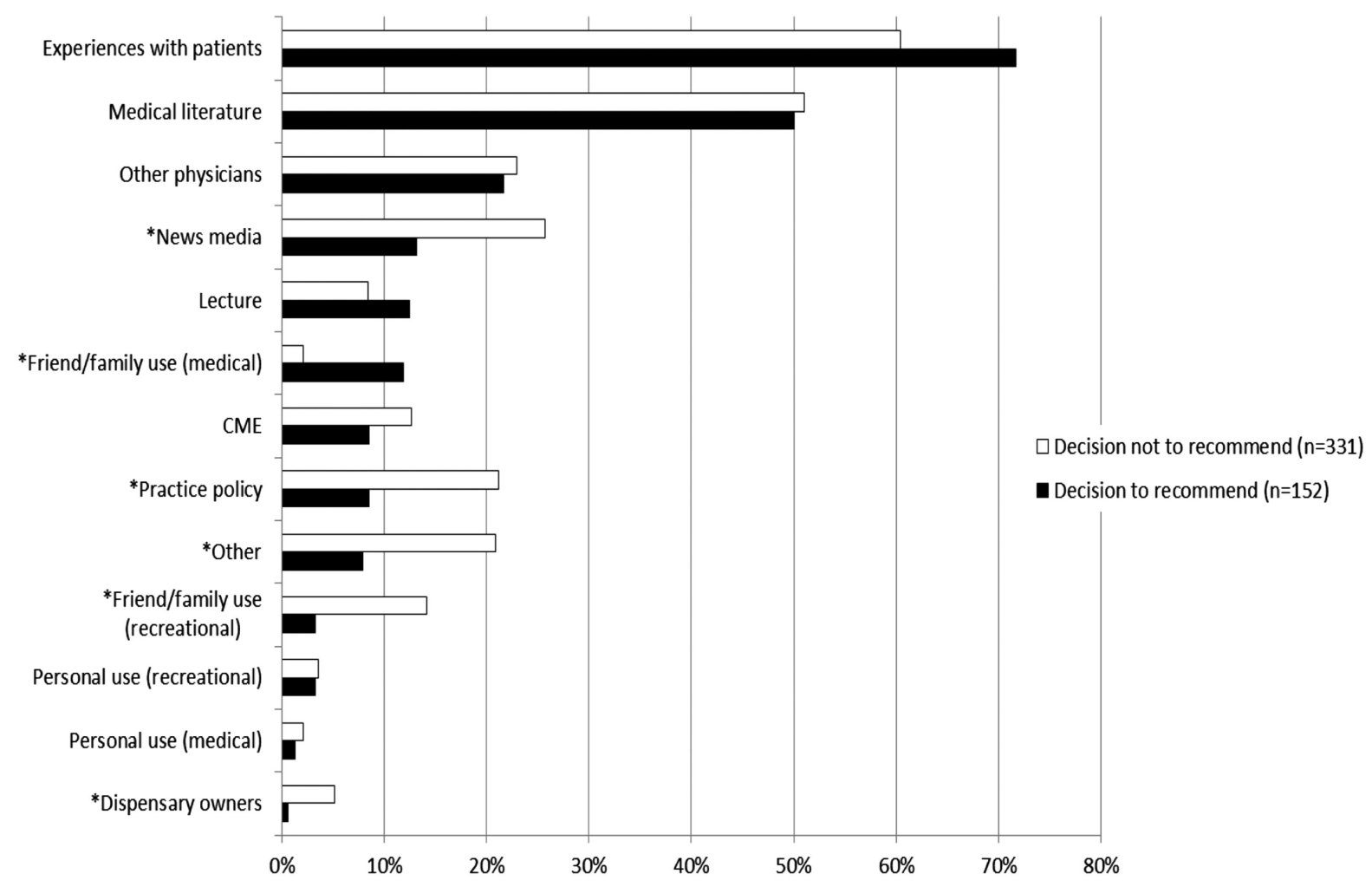

doctors should have financial relationships with dispensaries, and whether CME related to medical marijuana should be available to primary care physicians.

The survey did not ask directly if respondents had used marijuana personally; however, 20 respondents indicated personal use of marijuana as a source of information or an influence on the decision to recommend marijuana. Compared with other respondents, their opinions differed significantly in 3 areas (Table 3). As with the differences reported based on whether or not a physician had recommended marijuana for a patient, these differences represent significantly different proportions of agreement rather than opposing opinions.

Of the respondents, 18\% (93 physicians) chose to leave a comment at the end of the survey. The most common theme, found in $29 \%$ of comments, was concern that patients who were not truly sick were obtaining medical marijuana cards to have legal protection for recreational marijuana use. The second most common theme, found in $20 \%$ of comments, was a preference for outright legalization of marijuana in comparison to the current system. Sixteen percent of comments reflected the belief that physicians should not be involved in medical marijuana, and $10 \%$ of those who commented expressed a desire for further research and education about medical marijuana.

\section{Discussion}

Although some Colorado physicians have certified thousands of patients to use medical marijuana, our study indicates that the average primary care provider is doing so only occasionally, if at all. This survey also suggests that family physicians are recommending medical marijuana not only at lower rates, but also for different reasons than the highvolume recommenders in the state. Conditions such as cancer and cachexia were listed as frequent reasons for recommendation in our results, whereas these represent less than $2 \%$ of the patients on the registry. While $76 \%$ of physicians who had made a medical marijuana recommendation reported recommending marijuana at least once for "severe pain," this is far less than expected, given that $94 \%$ of the patients on the state registry are on it for this 
Table 2. Comparison of Survey Respondents Who Have Recommended Medical Marijuana for a Patient With Those Who Have Not

\begin{tabular}{|c|c|c|c|c|c|}
\hline \multirow[b]{3}{*}{ Survey Statement } & \multicolumn{4}{|c|}{ Recommended Marijuana for a Patient } & \multirow[b]{3}{*}{$P^{*}$} \\
\hline & \multicolumn{2}{|c|}{ Yes } & \multicolumn{2}{|c|}{ No } & \\
\hline & $\%$ & $\mathrm{n}$ & $\%$ & $\mathrm{n}$ & \\
\hline Physicians should recommend marijuana as a medical therapy. ${ }^{\dagger}$ & 77 & 87 & 11 & 233 & $<.001$ \\
\hline $\begin{array}{l}\text { Marijuana helps patients who suffer from chronic, debilitating } \\
\text { medical conditions. }\end{array}$ & 97 & 134 & 59 & 212 & $<.001$ \\
\hline $\begin{array}{l}\text { There are significant physical health benefits to using } \\
\text { marijuana. }{ }^{+}\end{array}$ & 72 & 99 & 26 & 234 & $<.001$ \\
\hline $\begin{array}{l}\text { Training about medical marijuana should be incorporated into } \\
\text { family medicine residency curricula. }\end{array}$ & 99 & 141 & 92 & 285 & .004 \\
\hline $\begin{array}{l}\text { The FDA should reclassify marijuana so that it is no longer a } \\
\text { schedule I drug. } .^{+}\end{array}$ & 75 & 119 & 33 & 280 & $<.001$ \\
\hline $\begin{array}{l}\text { There are significant mental health benefits to using } \\
\text { marijuana. }\end{array}$ & 44 & 82 & 14 & 254 & $<.001$ \\
\hline $\begin{array}{l}\text { Training about medical marijuana should be incorporated into } \\
\text { medical school curricula. }\end{array}$ & 99 & 138 & 93 & 272 & .02 \\
\hline Marijuana should be legalized for recreational use. ${ }^{\dagger}$ & 54 & 114 & 31 & 277 & $<.001$ \\
\hline $\begin{array}{l}\text { Physicians should have formal training about medical } \\
\text { marijuana prior to recommending it to patients. }\end{array}$ & 90 & 116 & 96 & 305 & .01 \\
\hline Marijuana can be addictive. & 74 & 125 & 91 & 297 & $<.001$ \\
\hline Using marijuana poses serious physical health risks. & 55 & 107 & 86 & 274 & $<.001$ \\
\hline Using marijuana poses serious mental health risks. & 57 & 103 & 89 & 282 & $<0.001$ \\
\hline
\end{tabular}

Percentages in each column represent agreement with the statement; numbers represent the total number of 'agree' or 'disagree' responses for that statement.

${ }^{*} \chi^{2}$ Test of independence.

${ }^{\dagger}$ A majority of the 2 groups differ on this statement.

FDA, US Food and Drug Administration.

indication. This gulf between physicians who are providing medical marijuana recommendations as a substantial portion of their practice and primary care providers who are far more likely to have a continuity relationship with a patient suggests that a continuity relationship influences provider behavior related to medical marijuana and may lead to more judicious recommendation of medical marijuana.
This study also shows the dissatisfaction of family physicians with Colorado's current system. It is troubling that more than $2 \%$ of the state's population is registered to use medical marijuana, and our results suggest that most primary care providers do not think there are significant health benefits to using medical marijuana and have substantial concerns about its potential harms. Furthermore, the

Table 3. Comparison of Survey Respondents Who Report Personal Marijuana Use as an Influence on Their Decision to Recommend or Not Recommend Marijuana To Those Who Do Not Report Personal Marijuana Use as an Influence

\begin{tabular}{|c|c|c|c|c|c|}
\hline \multirow[b]{3}{*}{ Survey Statement } & \multicolumn{4}{|c|}{ Reported Using Marijuana } & \multirow[b]{3}{*}{$P^{*}$} \\
\hline & \multicolumn{2}{|c|}{ Yes } & \multicolumn{2}{|c|}{ No } & \\
\hline & $\%$ & $\mathrm{n}$ & $\%$ & $\mathrm{n}$ & \\
\hline Marijuana can be addictive. & 56 & 16 & 88 & 408 & .002 \\
\hline Using marijuana poses serious mental health risks. & 54 & 13 & 82 & 374 & .02 \\
\hline $\begin{array}{l}\text { Doctors should have ongoing relationships with patients for whom } \\
\text { they recommend medical marijuana. }\end{array}$ & 89 & 19 & 98 & 439 & .03 \\
\hline
\end{tabular}

Percents represent respondents in each column that agree with the survey statement. Numbers represent total numbers of respondents who agreed or disagreed with the statement.

${ }^{*}$ Fisher Exact Test. 
current system for distribution of medical marijuana-for-profit marijuana dispensaries-were only approved of by a small minority of physicians who responded. The open-ended comments demonstrate a widely held belief that "medical marijuana" is being used predominantly by people who are well but want legal protection for recreational marijuana use, rather than by those with serious medical problems. Physicians surveyed support the reforms enacted in the 2010 Senate Bill 109, which requires a "bona fide physician-patient relationship" before the recommendation of medical marijuana and prohibits physicians from having financial relationships with marijuana dispensaries, but our results suggest the need for further amendments to Colorado's medical marijuana regulations. Consideration should be given to establishing more strict guidelines to determine who is a candidate for medical marijuana therapy, establishing an alternative means of distribution of medical marijuana to the current for-profit dispensary system, and requiring physicians to undergo formal training before recommending medical marijuana for patients.

Respondents to our survey demonstrate a strong desire for educational opportunities about medical marijuana at all levels of medical education. At this time there is little CME about medical marijuana available in the United States, and, as indicated in Figure 2, more surveyed physicians are getting information about medical marijuana from the news media and other physicians than they are from lectures or CME. CME resources should be developed in the near future, given the number of states where medical marijuana has been legalized and the consequent large number of physicians that potentially will be asked to provide medical certification for their patients.

When interpreting our findings, readers should keep in mind several cautions. Limitations of the study include the $30 \%$ response rate. Although a substantial number of total responses were received, it is possible that the views of those who completed the survey differ from those who did not complete the survey. However, the age and sex distributions of those who responded was similar to that of overall CAFP listserv members (Table 1), suggesting that this is a good sample of the target population. We sent the survey only to family physicians in Colorado, so our findings may not be generalizable to physicians of other specialties in Colorado or to physicians in other states that have different medical marijuana laws. However, because Colorado has the highest per-capita number of patients using medical marijuana and because Colorado maintains a registry of medical marijuana patients and compiles statistics about these patients, we believe it is the best setting for this study.

More research is needed on 2 fronts. First, further studies of other physician specialties and other states would confirm that these findings are generalizable beyond family physicians in Colorado. If so, these concerns should fuel interest in scrutinizing current medical marijuana laws and closely examining pending legislation being considered in other states. Second, medical marijuana needs a stronger evidence base. Our review of the literature found only limited high-quality evidence regarding the benefits of marijuana, and one of the primary concerns respondents voiced when able to comment was that there is not enough evidence about the risks and benefits of medical marijuana to know who, if anyone, might benefit from its use. Before physicians continue to recommend marijuana as medicine, we must have a better sense of when it has the potential to benefit our patients.

To our knowledge, this is the only study of physician attitudes toward medical marijuana ever done in a state where medical marijuana has been legalized. Policymakers in Colorado, and in other states where medical marijuana use has been authorized or where such legislation is being considered, should take into account this feedback from primary care physicians.

\section{References}

1. Colorado Department of Public Health and Environment. Colorado Medical Marijuana Registry home page. Available at: http://www.colorado.gov/cs/ Satellite/CDPHE-CHEIS/CBON/1251593016680. Accessed November 6, 2012.

2. Ogden DW. Investigations and prosecutions in states authorizing the medical use of marijuana. October 19, 2009. Available at: http://medicalmarijuana. procon.org/sourcefiles/USDOJNewPolicy.pdf. Accessed December 14, 2011.

3. Ingold J. Major changes are at hand for marijuana politics. Denver Post. October 3, 2010:A-01.

4. Wilsey B, Marcotte T, Tsodikov A, et al. A randomized, placebo-controlled, crossover trial of cannabis cigarettes in neuropathic pain. J Pain 2008;9:506-21.

5. Greenwald MK, Stitzer ML. Antinociceptive, subjective and behavioral effects of smoked marijuana in humans. Drug Alcohol Depend 2000;59:261-75. 
6. Ellis RJ, Toperoff W, Vaida F, et al. Smoked medicinal cannabis for neuropathic pain in HIV: a randomized, crossover clinical trial. Neuropsychopharmacology 2009;34:672-80.

7. Haney M, Gunderson EW, Rabkin J, et al. Dronabinol and marijuana in HIV-positive marijuana smokers. Caloric intake, mood, and sleep. J Acquir Immune Defic Syndr 2007;45:545-54.

8. Abrams DI, Jay CA, Shade SB, et al. Cannabis in painful HIV-associated sensory neuropathy: a randomized placebo-controlled trial. Neurology 2007; 68:515-21.

9. Wallace M, Schulteis G, Atkinson JH, et al. Dosedependent effects of smoked cannabis on capsaicininduced pain and hyperalgesia in healthy volunteers. Anesthesiology 2007;107:785-96.

10. Haney M, Rabkin J, Gunderson E, Foltin RW. Dronabinol and marijuana in $\mathrm{HIV}(+)$ marijuana smokers: acute effects on caloric intake and mood. Psychopharmacology (Berl) 2005;181:170-8.

11. Chang AE, Shiling DJ, Stillman RC, et al. Delata9-tetrahydrocannabinol as an antiemetic in cancer patients receiving high-dose methotrexate. A prospective, randomized evaluation. Ann Intern Med 1979;91:819-24.

12. Abrams DI, Hilton JF, Leiser RJ, et al. Short-term effects of cannabinoids in patients with $\mathrm{HIV}-1$ infection: a randomized, placebo-controlled clinical trial. Ann Intern Med 2003;139:258-66.

13. Levitt M, Faiman C, Hawks R, Wilson A. Randomized double-blind comparison of delta-9-tetrahydrocannabinol (THC) and marijuana as chemotherapy antiemetics. Proc Am Soc Clin Oncol 1984;3:91.

14. Greenberg HS, Werness SA, Pugh JE, et al. Shortterm effects of smoking marijuana on balance in patients with multiple sclerosis and normal volunteers. Clin Pharmacol Ther 1994;55:324-8.

15. Chang AE, Shiling DJ, Stillman RC, et al. A prospective evaluation of delta-9-tetrahydrocannabinol as an antiemetic in patients receiving adriamycin and cytoxan chemotherapy. Cancer 1981;47: 1746-51.
16. Joy J, Institute of Medicine. Marijuana and medicine: assessing the science base. Washington, DC: $\mathrm{Na}$ tional Academy Press; 1999.

17. Ashton CH. Pharmacology and effects of cannabis: a brief review. Br J Psychiatry 2001;178:101-6.

18. Hall $W$, Degenhardt L. Adverse health effects of nonmedical cannabis use. Lancet 2009;374:1383-91.

19. Moore THM, Zammit S, Lingford-Hughes A, et al. Cannabis use and risk of psychotic or affective mental health outcomes: a systematic review. Lancet 2007;370:319-28.

20. Pedersen W. Does cannabis use lead to depression and suicidal behaviours? A population-based longitudinal study. Acta Psychiatr Scand 2008;118:395403.

21. Tetrault JM, Crothers K, Moore BA, et al. Effects of marijuana smoking on pulmonary function and respiratory complications: a systematic review. Arch Intern Med 2007;167:221-8.

22. Tan WC, Lo C, Jong A, et al. Marijuana and chronic obstructive lung disease: a population-based study. CMAJ 2009;180:814-20.

23. Linn LS, Yager J, Leake B. Physicians' attitudes toward the legalization of marijuana use. West J Med 1989; $150: 714-7$.

24. Charuvastra A, Friedmann PD, Stein MD. Physician attitudes regarding the prescription of medical marijuana. J Addict Dis 2005;24:87-93.

25. Schwartz RH, Voth EA, Sheridan MJ. Marijuana to prevent nausea and vomiting in cancer patients: a survey of clinical oncologists. South Med J 1997;90: 167-72.

26. Doblin RE, Kleiman MA. Marijuana as antiemetic medicine: a survey of oncologists' experiences and attitudes. J Clin Oncol 1991;9:1314-9.

27. Nussbaum AM, Boyer JA, Kondrad EC. "But my doctor recommended pot": medical marijuana and the patient-physician relationship. J Gen Intern Med 2011;26:1364-7.

28. Colorado Department of Public Health and Environment. Colorado Senate Bill 109. Available at: http:// www.colorado.gov/cs/Satellite/CDPHE-CHEIS/ CBON/1251593017076. Accessed November 6, 2011. 